This document is confidential and is proprietary to the American Chemical Society and its authors. Do not copy or disclose without written permission. If you have received this item in error, notify the sender and delete all copies.

\title{
Development of a novel process integrating the treatment of sludge reject water and the production of polyhydroxyalkanoates (PHAs)
}

\begin{tabular}{|r|l|}
\hline Journal: & Environmental Science \& Technology \\
\hline Manuscript ID: & es-2015-01776v \\
\hline Manuscript Type: & Article \\
\hline Date Submitted by the Author: & $08-A p r-2015$ \\
\hline List of Authors: & $\begin{array}{l}\text { Fatone, Francesco; University of Verona, Dpt of Biotechnology } \\
\text { Frison, Nicola; University of Verona, Biotechnology } \\
\text { Katsou, Evina; Brunel University, Department of Mechanical, Aerospace } \\
\text { and Civil Engineering } \\
\text { Malamis, Simos; National Technical University of Athens, Department of } \\
\text { Water Resources and Environmental Engineering, School of Civil } \\
\text { Engineering } \\
\text { Oehmen, Adrian; Universidade Nova de Lisboa, Departamento de Química, } \\
\text { Faculdade de Ciências e Tecnologia }\end{array}$ \\
\hline
\end{tabular}




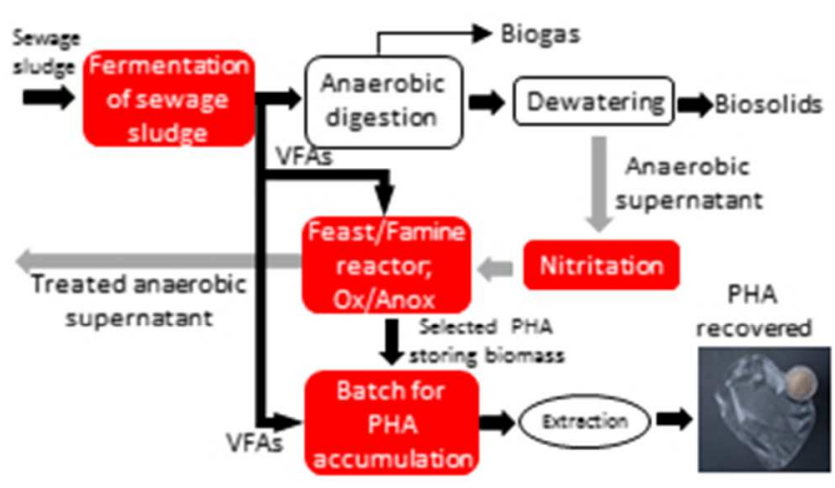

$84 \times 47 m m(96 \times 96$ DPI) 


\section{Title: Development of a novel process integrating}

\section{2 the treatment of sludge reject water and the}

\section{3 production of polyhydroxyalkanoates (PHAs)}

4

5 Nicola Frison,,$^{\dagger}$ Evina Katsou, ${ }^{\dagger,+}$ Simos Malamis, ${ }^{\dagger, \S}$ Adrian Oehmen, ${ }^{*}$ Francesco Fatone ${ }^{*},{ }^{\dagger}$

7 †University of Verona, Department of Biotecnology, Via Strada Le Grazie 15, 37134 -

8 Verona, Italy

$9 \stackrel{{ }^{\ddagger}}{ }$ Department of Mechanical, Aerospace and Civil Engineering, Brunel University, Kingston 10 Lane, UB8 3PH Uxbridge, Middlesex, UK.

$11{ }^{\S}$ Department of Water Resources and Environmental Engineering, School of Civil 12 Engineering, National Technical University of Athens, 5 Iroon Polytechniou St., 15780, 13 Athens, Greece.

$14{ }^{\sharp}$ UCIBIO, REQUIMTE, Departamento de Química, Faculdade de Ciências e Tecnologia, 15 Universidade Nova de Lisboa, 2829-516 Caparica, Portugal.

16 *Corresponding author: tel/fax: +39 045 8027965, e-mail: francesco.fatone@univr.it.

ABSTRACT. Polyhydroxyalkanoates (PHAs) from activated sludge and renewable organic 19 material could become an alternative product to traditional plastics since they are 20 biodegradable and biocompatible. In this work, the selection of PHA storing bacteria was 21 integrated to the side stream treatment for nitrogen removal via nitrite from sludge reject 
22 water. A novel process was developed and applied where the alternation of aerobic-feast and 23 anoxic-famine conditions accomplished selection of PHA storing biomass and nitrogen 24 removal via nitrite. Two configurations were examined: in configuration 1 the ammonium 25 conversion to nitrite occurred in the same reactor where the PHA selection process occurred, 26 while in configuration 2 two separate reactors were used. The results showed the selection of 27 PHA storing biomass was successful in both configurations, while the nitrogen removal 28 efficiency was much higher (almost 90\%) in configuration 2. The PHA selection degree was 29 evaluated by the volatile fatty acid (VFA) uptake rate (-qVFAs) and the PHA production rate 30 which were $182 \pm 14 \mathrm{mgCOD} / \mathrm{gX}$ h and $89 \pm 7 \mathrm{mgCOD} / \mathrm{gX}$ h respectively. The characterization 31 of biopolymers after the accumulation step, showed that it was composed of 332 hydroxybutyrate (3HB) (60\%) and 3-hydroxyvalerate (3HV) (40\%). The properties 33 associated with the produced PHA suggest that they are suitable for thermoplastic processing.

35 Keywords: polyhydroxyalkanoate (PHA); feast and famine regime; nitrogen removal 36 via nitrite; reject water

INTRODUCTION

39 Polyhydroxyalkanoates (PHA) are biodegradable polymers that can be produced by many 40 different types of bacteria. Compared to conventional synthetic polymers, PHAs possess 41 obvious ecological advantages since they are completely biodegradable and nontoxic ${ }^{1,2}$ and 42 can be produced from a renewable source. The family of PHA polymers, including 43 polyhydroxybutyrate (PHB) and PHB-related copolymers, is versatile and thus, presents 44 significant opportunities for marketability. PHA production from mixed cultures and 45 renewable organic wastes as a carbon source ${ }^{3,4,5}$ has become very attractive over the last 46 years due to the decrease in the production cost of the process ${ }^{6,7}$. Activated sludge from 
47 wastewater treatment plants (WWTPs) is a well-known source of PHA-storing organisms that 48 store these polymers as carbon and energy reserve for biomass growth. PHA production from 49 mixed cultures are accomplished by a sequence of operations which are the following ${ }^{8,9}:$ i) 50 acidogenic fermentation to produce volatile fatty acids (VFAs) from biodegradable organics;

51 ii) selection of PHA storing biomass in a sequencing batch reactor (SBR); iii) batch step to 52 maximise PHA accumulation in the bacteria.

53 The carbon limitation strategy under feast and famine conditions has been found to be

54 favourable for the enrichment and long-term cultivation of PHA producing communities, 55 while nitrogen limitation is a successful strategy that can be employed to accomplish high 56 PHA contents during the PHA production step ${ }^{10}$. However, these processes are aerobic and 57 thus are energy intensive; it is estimated that approximately $39 \mathrm{MJ}$ are needed to produce 1 $58 \mathrm{~kg}$ of PHA when the aerobic accumulation step is employed ${ }^{11,12}$.

59 The integration of nutrient removal in wastewater treatment systems with the PHA 60 production cycle is currently a challenge. Jiang et al. (2009) ${ }^{13}$, Morgan-Sagastume et al. $61(2010)^{14}$ and Pittmann et al. (2014) ${ }^{15}$ evaluated the potential for the enrichment of PHA62 storing organisms and the PHA-storage capacity of fermented sludge under different 63 operational conditions. It was found that PHA producing organisms could be successfully 64 enriched using the fermented sludge as feedstock, although very high nutrient loads did limit 65 the maximum level of PHA accumulation ${ }^{14}$. Morgan-Sagastume et al. also examined a new 66 concept of WWTP operation, where the selection of PHA storing biomass was accomplished 67 based on the conversion of the readily biodegradable chemical oxygen demand (COD) from 68 municipal wastewater without its pre-conversion to VFAs ${ }^{16}$. However, post-treatment was 69 required, in particular for enhanced nutrient removal of the treated effluent. Anterrieu et al $70(2014)^{17}$ studied the integration of PHA production with conventional nitrification and 71 denitrification for treating sugar beet factory waters, by operating with an anoxic feast and 
72 aerobic famine phase. In the sludge treatment line of municipal wastewater treatment plants,

73 however, the nutrient loads are typically much higher, and side-stream treatment is an

74 attractive option to avoid recycling these nutrients to the main treatment line. Short-cut

75 nitrogen removal processes via the nitrite pathway have been found to provide an attractive

76 means of achieving nutrient removal from sludge reject waters at lower operating expenses

77 compared to conventional nitrification-denitrification ${ }^{18}$. Frison et al. (2014) ${ }^{19}$ compared the

78 potential PHA storage of sludge under nitrifying and non-nitrifying conditions in batch

79 reactors, and found PHA production yields of $0.6 \mathrm{Cmol} \mathrm{PHA} / \mathrm{Cmol}$ VFA in both systems.

80 Nevertheless, the feasibility of integrating PHA production with nutrient removal via nitrite

81 has never been investigated.

82 In this work, a novel process for the potential integration of the side stream biological

83 nitrogen removal via nitrite with the selection of the PHA storing biomass from mixed

84 cultures treating anaerobic supernatant is examined. A modified pathway for nitrogen

85 removal was developed and applied in order to induce a feast and famine regime under

86 aerobic and anoxic conditions, respectively. The novel approach is based on (i) selection of a

87 PHA storing biomass in a sequencing batch reactor (SBR) by the alternation of aerobic feast

88 conditions for ammonia conversion to nitrite followed by anoxic famine (FF) conditions for

89 denitritation driven by internally stored PHA as carbon source; (ii) establishment of the

90 desired $\mathrm{COD} / \mathrm{N}$ ratio for the selection of PHA storing biomass by controlling the dosing of

91 the external carbon source and the nitrogen contained in the anaerobic supernatant. A side-

92 stream treatment technology able to integrate the conversion of fermented sludge to PHAs

93 with nutrient removal via nitrite would enable the simultaneous reduction of nutrient loads to

94 the main line of the WWTPs, lowering operational costs, with the recovery of a valuable

95 resource, PHA, providing further economic advantages to the WWTP. 


\section{MATERIAL AND METHODS}

\section{$99 \quad 2.1$ Experimental set-up}

100 Figure 1 shows two alternative configurations applied for nitrogen removal via nitrite and the

101 selection of PHA storing biomass downstream from the anaerobic digester. In configuration 1,

102 the nitrogen removal through nitritation/denitritation and the PHA selection process occurred

103 in a single SBR by applying a feast and famine regime. Specifically, during aerobic

104 conditions, ammonium was oxidized to nitrite, while during the anoxic famine conditions,

105 nitrite was reduced to nitrogen gas using the internally stored PHA as carbon source (Figure

106 1a). In configuration 2, two separate SBRs were used to accomplish the ammonium

107 conversion to nitrite and the selection of the PHA storing biomass (Figure 1b). Nitritation

108 was carried out in a dedicated SBR and then the liquid was fed to the selection reactor while

109 operated under famine conditions, accomplishing the denitritation using the stored PHA. In

110 the selection reactor, the $\mathrm{COD} / \mathrm{N}$ ratio was adjusted by feeding the anaerobic supernatant as

111 main source of nutrients (nitrogen and phosphorus).

112 The PHA accumulation step of the examined process was performed in a fed-batch reactor to 113 maximize the cellular PHA content of the biomass harvested from the selection stage. The

114 volatile fatty acids (VFAs) that are required for the feast conditions in the selection reactor

115 and the PHA accumulation in the batch reactor were recovered from the acidogenic

116 fermentation of sewage sludge. Fermented liquid from sewage sludge was used as VFA

117 source. The process is described in detail in the work of Longo et al. $(2015)^{20}$. The technical 118 details of the applied configurations are given below.

120 2.1.1 Configuration 1 (Figure 1a). An SBR having a working volume of 26 L was used for

121 the selection of PHA storing bacteria. Full details of the SBR are reported in the supporting 
122 information (SI). The cycles of the SBR consisted of 5 min of feeding, 300 min of reaction

123 phase (aerobic and anoxic), $15 \mathrm{~min}$ of settling and $5 \mathrm{~min}$ of discharge. Within the reaction

124 period, the aerobic phase was varied from 50 to $100 \mathrm{~min}$ during period 1 , and from 100 to

125150 min during period 2 (Configuration 1). This variation was introduced in order to compare

126 the effect of the availability of nitrite on the process. Two experimental periods were

127 performed using configuration 1 and adopting different $\mathrm{COD} / \mathrm{N}$ ratios (Table 1 ). The target

$128 \mathrm{COD} / \mathrm{N}$ was achieved by maintaining the volumetric organic loading rate (vOLR) stable at

$129674 \pm 72 \mathrm{gCOD} / \mathrm{m}^{3} \mathrm{~d}$ and altering the volumetric nitrogen loading rate (vNLR) by adjusting the

130 feeding of the anaerobic supernatant. Table 1 reports the operating conditions adopted during

131 the examined periods. In the first period, the feast conditions were established at the

132 beginning of the aerobic phase by applying a $\mathrm{COD} / \mathrm{N}$ ratio of $5.6 \pm 0.1 \mathrm{gCOD} / \mathrm{gN}$, while in the

133 second period the $\mathrm{COD} / \mathrm{N}$ was around $2.0 \pm 0.02 \mathrm{gCOD} / \mathrm{gN}$. The solids retention time (SRT)

134 was kept within the range of 12-15 days throughout each experimental period.

138 2.1.2 Configuration 2 (Figure 1b). In a first step, a nitritation SBR (N-SBR) was applied as a

139 pre-treatment stage in order to enhance the conversion of ammonium to nitrite (nitritation). A

140 detailed description of the operating conditions of the N-SBR are given in the SI. The

141 anaerobic supernatant exiting from the N-SBR reactor contained ammonium in the range of

14225 to $67 \mathrm{mgN} / \mathrm{L}$, while the average level of nitrite was approximately $350 \mathrm{mgN} / \mathrm{L}$. After

143 settling, the clarified effluent from the N-SBR was temporarily collected in a storage tank (80

144 L of volume) and then was fed to the selection SBR during the first 10-12 minutes of the

145 anoxic phase based on a volumetric nitrogen loading rate of $530 \pm 11 \mathrm{gN} / \mathrm{m}^{3} \mathrm{~d}$, which

146 corresponded to a volumetric nitrite loading rate of $423 \pm 95 \mathrm{gNO}_{2}-\mathrm{N} / \mathrm{m}^{3} \mathrm{~d}$. The loading rate of 
147 the carbon source during the feast was balanced with the nitrite loading rate applied during

148 the famine phase based on the ratio $2.2 \pm 0.1 \mathrm{gCOD} / \mathrm{gNO}_{2}-\mathrm{N}$. The operation cycle of the

149 selection SBR consisted of 50 minutes of aerobic phase, followed by 250 minutes of anoxic

150 conditions. The length for the feeding, settling and discharging were respectively 15,30 and

15115 minutes. The SRT was kept in the same range as for Configuration 1, 12-15 days.

152

\section{$153 \quad 2.2 \quad$ PHA accumulation}

154 The biomass was collected under famine conditions (end of the anoxic phase from the 155 selection SBR) and was concentrated gravimetrically by applying $30 \mathrm{~min}$ of settling. The aim 156 was to reduce the level of nutrients contained in the biomass obtained from the selection SBR.

157 Then, the biomass was placed in triplicate fed-batch glass reactors with working volumes of

$1581 \mathrm{~L}$ that were equipped with blowers, diffusers and probes for the measurement of the 159 dissolved oxygen (DO, type WTW, CellOx ${ }^{\circledR}$ 325), the $\mathrm{pH}$ (Polyplast Pro) and the 160 temperature (PT100). The on line signals were automatically recorded. The DO level was 161 always maintained above $2 \mathrm{mg} / \mathrm{L}$. The oxygen uptake rate (OUR) was determined using the 162 respirometer MARTINA (SPESS, Italy). The substrate was divided in fixed- volume aliquots 163 in order to dose manually each time approximately $1 \mathrm{gCOD} / \mathrm{L}$ of VFAs. New aliquots were 164 dosed when consecutive OUR values were $\sim 50 \%$ less than the previously recorded values. In 165 order to test different $\mathrm{COD} / \mathrm{N} / \mathrm{P}$ ratios during the PHA accumulation, three different carbon 166 sources were applied; a synthetic mixture of VFA (COD/N/P 100:0:0), sewage sludge

167 fermentation liquid (SFL) (COD/N/P 100:9.7:2.1) and sewage sludge fermentation liquid 168 with wollastonite (WSFL) (COD/N/P 100:7.8:0.06). In the latter, the use of wollastonite 169 during fermentation improves the $\mathrm{COD}_{\mathrm{VFA}} / \mathrm{NH}_{4}-\mathrm{N} / \mathrm{PO}_{4}-\mathrm{N}$ ratio, since it limits the net release 170 of nutrients (ammonia and phosphates). The duration of the accumulation test was 6-8 $\mathrm{h}$. 


\section{$172 \quad 2.3 \quad$ Calculations}

173 In this study the VFAs concentration, expressed as $\mathrm{mgCOD} / \mathrm{L}$, was calculated as follows:

$174 \quad \mathrm{VFAs}=\sum(\mathrm{HAc}+\mathrm{HPr}+\mathrm{HBt}+$ iso-HBt $+\mathrm{HPt}+\mathrm{isoHPt}+\mathrm{HHe}+\mathrm{HHp})$

175 where: HAc is acetic, $\mathrm{HPr}$ is propionic, $\mathrm{HBt}$ is butyric, iso-HBt is iso-butyric, HPt is

176 pentanoic, isoHPt is iso-pentanoic, HHe is hexanoic and HHp is heptaoic acid.

177 The PHA monomeric concentrations were converted into COD units by following the 178 oxidation stoichiometry: $1.38 \mathrm{mgCOD} / \mathrm{mg}(3$-hydroxybutyrate, HB), $1.63 \mathrm{mgCOD} / \mathrm{mg}(3-$ 179 hydroxyvalerate, $\mathrm{HV}$ ) and $1.82 \mathrm{mgCOD} / \mathrm{mg}(3$-hydroxyhexanoate, $\mathrm{HH})$. The total PHA 180 concentration was calculated as follows:

$$
\text { PHA }(\mathrm{mgCOD} / \mathrm{L})=\sum(\mathrm{PHB}+\mathrm{PHV}+\mathrm{PHH})
$$

where: PHB is polyhydroxybutyrate; $\mathrm{PHV}$ is polyhydroxyvalerate; $\mathrm{PHH}$ is

183 polyhydroxyhexanoate.

The amount of PHA (g/L) was subtracted from the VSS $(\mathrm{g} / \mathrm{L})$ to calculate the concentration 186 of the active biomass $(\mathrm{X}, \mathrm{g} / \mathrm{L})$. The latter was transformed as COD concentration by the 187 stoichiometric ratio of $1.42 \mathrm{gCOD} / \mathrm{gVSS}$.

188 The fraction of the PHA in the biomass was calculated considering the following equation:

$$
\operatorname{PHA}(\%)=\frac{\mathrm{gPHA}}{\mathrm{gVSS}} \times 100
$$

190 where the gPHA and the VSS were respectively the PHA and the volatile suspended solids of

191 the biomass. The specific VFA uptake rate (-qVFA, $\mathrm{mgCOD} / \mathrm{gCOD} \mathrm{X}$ ) and the PHA storage 192 rate (qPHA, mgCOD/gCOD $\mathrm{X}$ ), were determined by linear regression analysis by plotting the 193 concentarion of VFAs and PHA as a function of time. The results were normalized for the

194 active biomass concentration. The rates were standardized at $20^{\circ} \mathrm{C}$ of temperature by the 195 Arrenhius equation ${ }^{21}$. The PHA storage yield ( $\left.\mathrm{Y}_{\mathrm{PHA} / \mathrm{VFA}}, \mathrm{gCOD}_{\mathrm{PHA}} / \mathrm{gCOD}_{\mathrm{VFA}}\right)$ and the growth 
196 yield $\left(\mathrm{Y}_{\mathrm{X} / \mathrm{VFA}}, \mathrm{gCOD}_{\mathrm{X}} / \mathrm{gCOD}_{\mathrm{VFA}}\right)$ were calculated as the ratio between each maximum 197 specific rate (qPHA and $\mathrm{qX}$, respectively) and the -qVFA.

198

\section{$199 \quad 2.4 \quad$ Analytical methods}

200 The concentrations of the mixed liquor suspended solids (MLSS), mixed liquor volatile 201 suspended solids (MLVSS), chemical oxygen demand (COD), soluble chemical oxygen 202 demand (SCOD), total Kjeldahl nitrogen (TKN), ammonium $\left(\mathrm{NH}_{4}-\mathrm{N}\right)$, phosphorous (TP) 203 were determined according to standard methods ${ }^{22}$. Nitrite $\left(\mathrm{NO}_{2}-\mathrm{N}\right)$, nitrate $\left(\mathrm{NO}_{3}-\mathrm{N}\right)$ and 204 phosphate $\left(\mathrm{PO}_{4}-\mathrm{P}\right)$ concentration were determined by the ion chromatograph Dionex ICS-900 205 with AS14 as column, while the concentration of HAc, HPr, HBt, iso-HBt, HPt, isoHPt and 206 HHe and heptaoic acid was determined by liquid chromatography through a Dionex ICS2071100 with IonPac ICE-AS1 as column. Samples of biomass were collected from the selection 208 and accumulation reactors and the liquor was removed through centrifugation. Then, the 209 thickened biomass was freeze-dried with a lyophilisation unit (Lio 5P, 5Pascal, Milano, Italy) 210 and analysed for the content of PHA using the method developed by Lanham et al., $(2013)^{23}$.

211 The specific ammonium uptake rate (sAUR) and specific nitrogen uptake rate (sNUR) were 212 determined in situ following the procedures that are given in SI. The nitrogen mass balances 213 were calculated for each experimental period (see SI).

214 The final biopolymers produced during the accumulation stage were also extracted from the 215 freeze dried biomass by applying the chloroform method (50 $\mathrm{mL} / \mathrm{g}$ of freeze dried biomass)

216 followed by the addition of methanol as precipitation agent ${ }^{1}$. Then, the biopolymers were 217 analysed through size exclusion chromatography (SEC, Polymer Lab) in order to determine 218 the molecular number $\left(\mathrm{M}_{\mathrm{n}}\right)$, average molecular weights $\left(\mathrm{M}_{\mathrm{w}}\right)$ and the polydispersity indices 219 (PDI). The glass transition temperature ( $\mathrm{Tg})$, melting temperature $\left(\mathrm{T}_{\mathrm{m}}\right)$ and melting enthalpy 
220 (DHm) were determined by differential scanning calorimetry (DSC, TA Instruments). More 221 information about the procedures are available on SI.

223 RESULTS AND DISCUSSION

\section{$224 \quad 3.1$ Efficiency of single stage reactor configuration}

225 The impact of combining the ammonium oxidation to nitrite, denitritation and selection of the 226 PHA storing biomass in a single reactor was evaluated by altering the percentage of the 227 aerobic versus the total cycle duration. The aerobic reaction duration varied from 17 to $30 \%$

228 (Period 1, days 0 -50) and from 30 to 50\% (Period 2, days $51-108$ ) of the total cycle duration. 229 In configuration 1, the main electron acceptor available during the feast conditions was 230 oxygen, while nitrite was the only electron acceptor present during the famine period. If no 231 additional external carbon source is present, an efficient famine condition under the anoxic 232 environment may occur when enough nitrite is available for the complete utilization of PHA. 233 Thus, the stoichiometry of the process imposes that the ratio of PHA stored (as COD) to the 234 nitrite denitrified should not exceed the stoichiometric value of $\left[1.72 /\left(1-\mathrm{Y}_{\mathrm{HD}}\right)\right]$ $235\left(\mathrm{gCOD}_{\mathrm{PHA}} / \mathrm{gNO}_{2}-\mathrm{N}\right)$, where $\mathrm{Y}_{\mathrm{HD}}$ is the growth yield of the denitrifying bacteria using storage 236 compounds.

238 3.1.1 Period 1. At the beginning of period 1, the biomass showed a typical feast and famine 239 response (the duration of the feast phase was approximately $16 \%$ of the total cycle duration), 240 although the ammonium conversion to nitrite was $36 \pm 13 \%$, producing only $6.5 \mathrm{mgNO}_{2}-\mathrm{N} / \mathrm{L}$ 241 at the completion of the aerobic phase (Figure $2 \mathrm{a}$ and $\mathrm{b}$ ). During feast conditions the -qVFA 242 was $96 \pm 33 \mathrm{mgCOD} / \mathrm{gX} \mathrm{h}$ (Figure 5 and Table 2). Despite the relatively high DO 243 concentration during the aerobic phase, within the first 15 days ( $0-15$ days) the nitrification 244 activity of the biomass seems to be negatively affected by the presence of VFA during the 
245 feast phase, since the sAUR decreased from the initial value of $15-18 \mathrm{mgN} / \mathrm{gX} \mathrm{h}$ (measured 246 in the inoculum) to $4.18 \pm 1.93 \mathrm{mgN} / \mathrm{gX} \mathrm{h}$. This is likely due to the faster biomass growth rate 247 of VFA consuming heterotrophic organisms as compared to nitrifying autotrophs (Henze et al. 248 2000). As a consequence, the ratio between the PHA stored (COD based) and the nitrite 249 concentration at the beginning of the anoxic phase was $15.5 \mathrm{gCOD} / \mathrm{gNO}_{2}-\mathrm{N}$, which was too 250 high to allow for complete PHA degradation under famine conditions. The lack of nitrite 251 available under anoxic conditions resulted in poor nitrogen removal efficiency for this period 252 (Table 2). Under denitrifying famine conditions, the efficiency of PHA consumption was not 253 more than $41 \pm 1 \%$ due to the shortage of nitrite as electron acceptor (Figure 5) and the PHA 254 accumulated in the selection reactor up to $0.21 \mathrm{gCOD}_{\mathrm{PHA}} / \mathrm{gCOD}_{\mathrm{X}}$ (Figure $2 \mathrm{~b}$ ). Maintaining 255 efficient famine conditions where the stored PHA is consumed has been found to be of high 256 importance in achieving a selected culture with a high PHA storage capacity ${ }^{24}$.

257 During the first period, the -qVFA decreased down to $4 \mathrm{mgCOD} / \mathrm{gX}$ h (day 28 , Figure 5) and 258 the $\mathrm{Y}_{\mathrm{PHA} / \mathrm{VFA}}$ from 0.31 to $0.07 \mathrm{gCOD} / \mathrm{gCOD}_{\mathrm{VFA}}$ (Figure 5). To promote the growth of the 259 PHA storing bacteria during the anoxic/famine conditions, the ammonium conversion to 260 nitrite was enhanced by doubling the duration of the aerobic phase, while maintaining 261 constant the applied vNLR and the vOLR (days 29 to 50). The amount of nitrite increased up 262 to $26 \mathrm{mgNO}_{2}-\mathrm{N} / \mathrm{L}$ and the nitrogen removal efficiency was $70.1 \%$. The higher duration of the 263 aerobic phase favoured the degradation of the PHA up to 66\% (Figure 5, day 39) under 264 famine conditions, due to the more abundant presence of electron acceptors. However, it was 265 found that $\sim 30 \%$ of the previously stored PHA was consumed under aerobic/famine 266 conditions before the anoxic-famine period initiated. The increase in the aerobic period 267 resulted in an aeration time that exceeded the feast phase duration for the applied vOLR, 268 leading to some aerobic PHA degradation. The PHA content at the end of the anoxic famine 269 conditions was constantly below $0.01 \mathrm{gCOD} / \mathrm{gCOD}$. Furthermore, at the end of period 1 
270 (days 29-50), the -qVFA increased together with the $\mathrm{Y}_{\mathrm{PHA} / \mathrm{VFA}}$ up to $108 \pm 18 \mathrm{mgCOD} / \mathrm{gX} \mathrm{h}$ 271 and $230 \pm 150 \mathrm{mgCOD} \mathrm{PHA}_{1} / \mathrm{gCOD}_{\mathrm{VFA}}$ (Figure 5), respectively.

272

273 3.1.2 Period 2. Once the feast and famine cycle and the nitrogen removal efficiency showed a 274 steady profile, the vNLR was increased to $0.38 \pm 0.03 \mathrm{kgN} / \mathrm{m}^{3} \mathrm{~d}$ in order to enhance the 275 treatment capacity of the system, while maintaining constant the vOLR. The duration of the 276 aerobic reaction phase was slightly altered during this period in order to ensure sufficient 277 conversion of ammonium to nitrite and to control the $\mathrm{COD}_{\mathrm{PHA}} / \mathrm{NO}_{2}-\mathrm{N}$ ratio between 2.0 and $2782.2 \mathrm{gCOD} / \mathrm{gNO}_{2}-\mathrm{N}$ when the anoxic/famine condition took place. More specifically, aerobic 279 conditions were maintained for $45 \pm 12 \%$ of the total cycle duration. The sAUR slightly 280 increased up to $5.5 \pm 0.5 \mathrm{mgN} / \mathrm{gX} \mathrm{h}$ and within $100-150 \mathrm{~min}$ of aerobic conditions, the nitrite 281 concentration was $32 \mathrm{mgN} / \mathrm{L}$. As result, a stable feast-famine regime was established during 282 days 51-108 (Figure 3 a and b). Under aerobic conditions, the average -qVFA was $136 \pm 29$ $283 \mathrm{mgCOD} / \mathrm{gX} \mathrm{h}$ (Figure 5), resulting in the decrease of the ratio of the feast to the total cycle 284 length from $18-19 \%$ (period 1) to $14-15 \%$ (period 2). The higher capacity of the biomass to 285 store PHA was confirmed by the $\mathrm{Y}_{\mathrm{PHA} / \mathrm{VFA}}$, which increased from $230 \pm 15$ (period 1) to $286371 \pm 15$ (period 2) $\mathrm{mgCOD}_{\mathrm{PHA}} / \mathrm{gCOD}_{\mathrm{VFA}}$ (Figure 5). Furthermore, $72 \pm 16 \%$ of the PHA was 287 degraded during the aerobic and anoxic famine conditions (Figure 5). Although the 288 denitritation efficiency of the denitrificable nitrogen was always higher than $94 \%$, the 289 average nitrogen removal in the same period was low $(48.8 \pm 3.4 \%$, average value, see $\mathrm{SI})$ 290 since a significant residual ammonium concentration remained. Thus, an alternate process 291 configuration (Configuration 2) was studied in order to increase nitrogen removal and 292 augment PHA production further.

293

(Figure $2 \mathrm{a}$ and $2 \mathrm{~b}$ )

294

(Figure $3 \mathrm{a}$ and $3 \mathrm{~b}$ ) 
(Figure 5)

\subsection{Efficiency of the configuration with two separate reactors}

299 To cope with the residual ammonium concentration, configuration 2 applied a two stage 300 process for nitritation and selection of PHA storing biomass. Ammonium was first oxidized 301 in the N-SBR (Figure 1b) and then the liquid was fed in the selection reactor when the anoxic

302 reaction phase started. Figure 4 ( $a$ and $b$ ) shows the typical profiles of nitrogen, PHA and

303 VFA concentration that were obtained in the selection SBR after adopting configuration 2 304 (day 108 to 150 ). The VFA were completely depleted within the first 30 min of the aerobic 305 phase, resulting in a $-\mathrm{qVFA}$ of $182 \pm 14 \mathrm{mgCOD} / \mathrm{gX} \mathrm{h}$ (Figure 5). Under feast conditions, the 306 PHA of the biomass rapidly increased at a qPHA of $89 \pm 7 \mathrm{mgCOD} / \mathrm{gX} \mathrm{h}$, which is higher 307 compared to the respective value of configuration 1 . The $\mathrm{Y}_{\mathrm{PHA} / \mathrm{VFA}}$ increased as well, from $308371 \pm 15$ to $433 \pm 10 \mathrm{mgCOD}{ }_{\mathrm{PHA}} / \mathrm{gCOD}_{\mathrm{VFA}}$ (Figure 5). After $50 \mathrm{~min}$ of aerobic phase, the 309 anoxic-famine phase started by switching off the blower and feeding the effluent of the N-

310 SBR. In configuration 2, nitrite was the only electron acceptor for the PHA degradation for 311 denitritation during the famine conditions. Furthermore, this strategy allowed a better control

312 of the applied $\mathrm{COD} / \mathrm{NO}_{2}-\mathrm{N}$, avoiding nitrite limitation in the famine phase and enabling 313 higher nitrogen removal efficiency (Table 2). Figure 4(a) shows the increase of the nitrite 314 content during the anoxic phase (up to $75 \mathrm{mgNO}_{2}-\mathrm{N} / \mathrm{L}$ ). During the famine conditions, the

315 PHA was consumed, reaching a minimum concentration of $0.006 \mathrm{gCOD}_{\mathrm{PHA}} / \mathrm{gCOD}$ at the end 316 of the anoxic cycle. This fact indicates that almost all the stored PHAs were degraded. The 317 PHA consumption efficiency was indeed higher when compared with that of configuration 1 318 (83 $\pm 4 \%$, Figure 5). Additionally, during the anoxic phase, the ammonium nitrogen decreased 319 from 28 to $21 \mathrm{mgN} / \mathrm{L}$; this reduction was correlated with the growth of the PHA storing 
320 bacteria. The rate of PHA degradation during the famine phase is independent of the type of

321 electron acceptor present ${ }^{16}$. The famine (anoxic) duration and the carbon stored were enough 322 to achieve almost $90 \%$ of denitritation. The nitrite at the end of the cycle decreased to 15 $323 \mathrm{mgNO}_{2}-\mathrm{N} / \mathrm{L}$. However, the nitrite concentration in the effluent was $7-10 \mathrm{mgNO}_{2}-\mathrm{N} / \mathrm{L}$, 324 indicating that denitritation occurred during the sedimentation but without any rising of 325 sludge. This was confirmed by the low content of solids in the effluent $(<15 \mathrm{mg} / \mathrm{L})$.

326 Configuration 2 is advantageous compared to configuration 1, since it enhances the overall 327 nitrogen removal efficiency up to $79 \pm 4.4 \%$, when applying a vNLR of $0.53 \pm 0.11 \mathrm{kgN} / \mathrm{m}^{3} \mathrm{~d}$. 328 Furthermore, the PHA production rate and yield per VFA were enhanced. Coupling side329 stream nitritation/denitritation processes with PHA production through mixed microbial 330 cultures has the potential to be economically advantageous, since recovery of a valuable 331 resource can be incorporated into the wastewater treatment plant, while reducing nutrient 332 loads to the head of the plant, reducing operational costs in the mainstream. Furthermore, the 333 implementation of anoxic conditions during the famine phase of PHA production systems by 334 mixed cultures is a useful means of saving aeration energy.

(Table 2)

\subsection{PHA accumulation}

338 The PHA storage capacity gradually increased during the overall experimental period, as a 339 confirmation of a good acclimation response of the selected biomass. In this work, the 340 maximal capacity of biomass to store PHA was examined under the operation of 341 configuration 2, when better PHA productivity was obtained. After 8 hours, the biomass was 342 able to accumulate up to $19 \pm 2 \%, 21 \pm 5 \%$ and $41 \pm 4 \%$ (gPHA/gVSS x 100 ) when sewage 343 sludge fermentation liquid (COD:N:P $=100: 9.7: 2.1$, no $\mathrm{N}$ or $\mathrm{P}$ limitation), primary sludge 344 fermentation liquid with wollastonite (COD:N:P = 100:7.8:0.06, P- limited), and a synthetic 
345 mixture of VFA (COD:N:P = 100:0:0, N and P-limited) were fed, respectively (Table 3). The

346 results were in the same range with other authors which used fermentation liquid from

347 sewage sludge ${ }^{14}$. The carbon source was also used as substrate for biomass growth. Despite

348 the fact that the synthetic mixture of VFAs presented a favourable ratio of COD:N:P to limit

349 the growth of new bacteria, the yield of active biomass per substrate consumed varied

350 between 0.20 and $0.28 \mathrm{gCOD} / \mathrm{gCOD}$. This was due to the nitrogen and phosphorus present in

351 the liquor + biomass withdrawn from the selection reactor for the accumulation tests,

352 lowering the COD driven for PHA production. Limiting further the presence of nutrients

353 during the accumulation step would be of interest for process optimisation purposes in future

354 research in order to maximise PHA productivity.

355 The biopolymers that were produced with the WSFL and SFL had similar characteristics in 356 terms of $3 \mathrm{HV}$ and $3 \mathrm{HB}$ percentage (Table 3). With the use of the synthetic mixture of VFAs 357 as carbon source, the biopolymer was composed of $35 \% \mathrm{HB}$ and $65 \%$ of $\mathrm{HV}$ and $\mathrm{HH}$. This 358 correlates well with the VFA profile added during each test, where the synthetic VFA 359 mixture contained a higher fraction of HV precursors (Table 3).

360

(Table 3)

361 Characterisation of the recovered PHA supports their applicability for thermoplastic 362 processing. The analyses revealed that the biopolymers were composed of long molecular 363 chains, with a similar molecular weight varying between $6 \times 10^{5}$ and $8 \times 10^{5} \mathrm{~g} / \mathrm{mol}$ and also a 364 similar chain length distribution (PDI 1.22-1.35). In general, the low crystallinity in 365 combination with a low $\operatorname{Tg}$ (between -1.1 to $-0.5^{\circ} \mathrm{C}$ ) indicate biopolymers with amorphous 366 characteristics $^{14}$. Overall, the biopolymer characteristics observed were in the same range as 367 observed in other studies ${ }^{14,24}$. 


\subsection{Aeration demand of the novel process and future perspectives}

371 The experimental results acquired in this study were used to estimate the potential aeration 372 savings (thus, decrease in energy costs) when the process for PHA production is integrated in 373 the side stream nitrogen removal via nitrite from the anaerobic supernatant. The calculations 374 are reported in detail in the SI (Table S5). The production of $1 \mathrm{~kg}$ of PHA with $60 \% \mathrm{HB}$ and $37540 \% \mathrm{HV}$, required the equivalent of $3.7 \mathrm{kgCOD}$ of VFA, which are partially oxidized (1.3 $376 \mathrm{kgCOD})$ and partially used to grow new bacterial cells $\left(0.9 \mathrm{kgCOD}, \mathrm{Y}_{\mathrm{X} / \mathrm{VFA}}=0.25\right.$ $377 \mathrm{kgCOD} / \mathrm{kgCOD})$ during the accumulation stage. The amount of oxygen needed during the 378 accumulation can be estimated to be $1.7 \mathrm{kgO}_{2}$ considering that $1.3 \mathrm{kgO}_{2}$ is required for every $379 \mathrm{~kg}$ of COD that is oxidized ${ }^{25}$. The percentage of PHA in the biomass could achieve $35 \%$ 380 (gPHA/gVSS), thus $2.6 \mathrm{~kg}$ of active biomass should be produced during the feast/famine 381 stage by providing $10.2 \mathrm{~kg}$ of COD (VFA). The oxygen required for the selection stage is the 382 oxygen provided only during the aerobic feast phase, which represents $20 \%$ of the reaction 383 phase duration of the SBR. The oxygen estimated during the aerobic feast phase is $4.6 \mathrm{~kg}$ of $384 \mathrm{O}_{2}$, meaning that the overall process required $6.4 \mathrm{kgO}_{2}$ for $1 \mathrm{~kg}$ of PHA. Compared with the 385 conventional aerobic PHA production (selection and accumulation phase), the aerobic and 386 anoxic feast/famine selection plus aerobic accumulation process could save approximately $38758 \%$ of the oxygen requirement.

388 In the current work, the biological nitrogen removal via nitrite was integrated with the 389 selection of PHA storing biomass in the sludge treatment line. The integration of PHA 390 production within a WWTP at full scale was the driving force for the development of our 391 novel treatment scheme. A twofold objective is achieved in the novel process that is 392 proposed; enhanced selection of PHA stored biomass and wastewater and reject water 393 treatment for nitrogen removal. Thus, the examined process provides true added value 394 towards the effective treatment of nitrogen in highly contaminated effluents within WWTPs, 
395 aiming at the same time to maximize resource recovery through the polymer production,

396 which could enhance the sustainability of the WWTP.

397

398

\section{ACKNOWLEDGMENT}

399 This study was carried out within the framework of the European projects LIVE WASTE 400 (LIFE $12 \mathrm{ENV/CY/000544).}$

401

4024 References

403 1. Madkour, M. H.; Heinrich, D.; Alghamdi, M. A.; Shabbaj, I. I.; Steinbüchel, A., PHA 404 Recovery from Biomass. Biomacromolecules 2013, 14, 2963-2972.

405 2. Yu, J.; Chen, L. X. L., The Greenhouse Gas Emissions and Fossil Energy 406 Requirement of Bioplastics from Cradle to Gate of a Biomass Refinery. Environ. Sci. 407 Technol. 2008, 42, 6961-6966.

408 3. Bengtsson, S.; Pisco, A. R.; Johansson, P.; Lemos, P. C.; Reis, M. A. M., Molecular 409 weight and thermal properties of polyhydroxyalkanoates produced from fermented sugar 410 molasses by open mixed cultures. J. Biotechnol. 2010, 147 (3), 172-179.

411 4. Dionisi, D.; Caruccia, G.; Petrangeli Papinia, M.; Riccardi, C.; Majone, M.; Carrasco, 412 F., Olive oil mill effluents as a feedstock for production of biodegradable polymers. Water 413 Res. 2005, 39, $2076-2084$.

414 5. Yuan, H.; Chen, Y.; Zhang, H.; Jiang, S.; Zhou, Qi.; Gu, G. Improved Bioproduction 415 of Short-Chain Fatty Acids (SCFAs) from Excess Sludge under Alkaline Conditions. Environ. 416 Sci. Technol., 2006, 40 (6), pp 2025-2029.

417 6. Braunegg, G.; Bona, R.; Koller, M., Sustainable polymer production. Polymer418 Plastics Technol. Eng. 2004, 43 (6), 1779-1793.

419 7. Research Watch. Environ. Sci. Tecnol. 1996, 30 (9), 1996. 
420 8. Tamis, J.; Marang, L.; Jiang, Y.; van Loosdrecht, M. C. M.; Kleerebezem, R., 421 Modeling PHA-producing microbial enrichment cultures - towards a generalized model with 422 predictive power. New Biotechnol. 2014, 31 (4).

423 9. Dionisi, D.; Majone, M.; Tandoi, V.; Beccari, M., Sequencing batch reactor: influence 424 of periodic operation on performance of activated sludge in biological a astewater treatment. 425 Ind. Eng. Chem. Res. 2001, 40, 5110- 5119.

426 10. Johnson, K.; Kleerebezem, R.; van Loosdrecht, M. C. M., Influence of the C/N ratio 427 on the performance of polyhydroxybutyrate (PHB) producing sequencing batch reactors at 428 short SRTs. Water Res. 2010, 44, 2141-2152.

429 11. Meesters, K. H. P. Production of poly (3 hydroxyalkanoates) from waste streams; 430 Technical University of Delft: Delft, 1998.

431 12. Ju, J.; Si, Y. A Dynamic Study and Modeling of the Formation of 432 Polyhydroxyalkanoates Combined with Treatment of High Strength Wastewater. Environ. Sci. 433 Technol. 2001, 35, 3584-3588.

434 13. Jiang, Y.; Chen, Y.; Zheng, X., Efficient polyhydroxyalkanoates production from a 435 waste-activated sludge alkaline fermentation liquid by activated sludge submitted to the 436 aerobic feeding and discharge process. Environ. Sci. Technol. 2009, 43, 7734-7741.

437 14. Morgan-Sagastume, F.; Karlsson, A.; Johansson, P.; Pratt, S.; Boon, N.; Lant, P.; 438 Werker, A., Production of polyhydroxyalkanoates in open, mixed cultures from a waste 439 sludge stream containing high levels of soluble organics, nitrogen and phosphorus. Water Res. $440 \quad 2010,5196-5211$.

441 15. Pittmann, T., Steinmetz, H. Polyhydroxyalkanoate production as a side stream process 442 on a municipal waste water treatment plant. Biores. Technol. 2014, 167, 297-302

443 16. Morgan-Sagastume, F.; Valentino, F.; Hjort, M.; Cirne, D.; Karabegovic, L.; Gerardin, 444 F.; Johansson, P.; Karlsson, A.; Magnusson, P.; Alexandersson, T.; Bengtsson, S.; Majone, 
445 M.; Werker, A., Polyhydroxyalkanoate (PHA) production from sludge and municipal 446 wastewater treatment. Water Sci. Technol. 2014, 69, 177-184.

447 17. Anterrieu, S., Quadri, L., Geurkink, B., Dinkla, I., Bengtsson, S., Arcos-Hernandez, 448 M., Alexandersson, T., Morgan-Sagastume, F., Karlsson, A., Hjort, M., Karabegovic, L., 449 Magnusson, P., Johansson, P., Christensson, M., Werker A. Integration of biopolymer 450 production with process water treatment at a sugar factory. $N$ Biotechnol. 2014, 31(4), 308451 323; DOI: 10.1016/j.nbt.2013.11.008.

452 18. Cervantes, F.J. Environmental Technologies to Treat Nitrogen Pollution. IWA 453 Publishing, London, 2009.

454 19. Frison, N.; Katsou, E.; Malamis, S.; Oehmen, A.; Fatone, F., Nutrient removal via 455 nitrite from reject water and polyhydroxyalkanoate (PHA) storage during nitrifying 456 conditions. J. Chem. Technol. Biotechnol. 2014; DOI 10.1002/jctb.4487

457 20. Longo, S., Katsou, E., Malamis, S., Frison, N., Renzi, D., Fatone, F. Recovery of 458 volatile fatty acids from fermentation of sewage sludge in municipal wastewater treatment 459 plants. Biores. Technol. 2015, 175, 436-444.

460 21. Carrera, J., Vicent, T., Lafuente, F.J. Influence of temperature on denitrification of an 461 industrial high-strength nitrogen wastewater in a two-sludge system. Wat. SA. 2003, 29, 1146216.

463 22. APHA, Standard Methods for the Examination of Water and Wastewater, 20th ed.; 464 American Public Health Association: Washington, DC, 1998.

465 23. Lanham, A.B., Ricardo, A.R., Albuquerque, M.G.E., Pardelha, F, Carvalheira, M., 466 Coma, M., Fradinho, J., Carvalho, G., Oehmen, A., Reis, M.A.M. Determination of the 467 extraction kinetics for the quantification of polyhydroxyalkanoate monomers in mixed 468 microbial systems. Proc. Bioch. 2013, 48, 1626-1634. 
469 24. Albuquerque, M.G.E., Torres, C.A.V., Reis, M.A.M., Polyhydroxyalkanoate (PHA) 470 production by a mixed microbial culture using sugar molasses: Effect of the influent substrate 471 concentration on culture selection. Wat. Res. 2010, 44, 3419-343318.

472 25. Gurieff, N,; Lant, P., Comparative life cycle assessment and financial analyses of 473 mixed culture polyhydroxyalkanoate production. Bioresour. Technol. 2007, 3393-3403.

474

475 
476
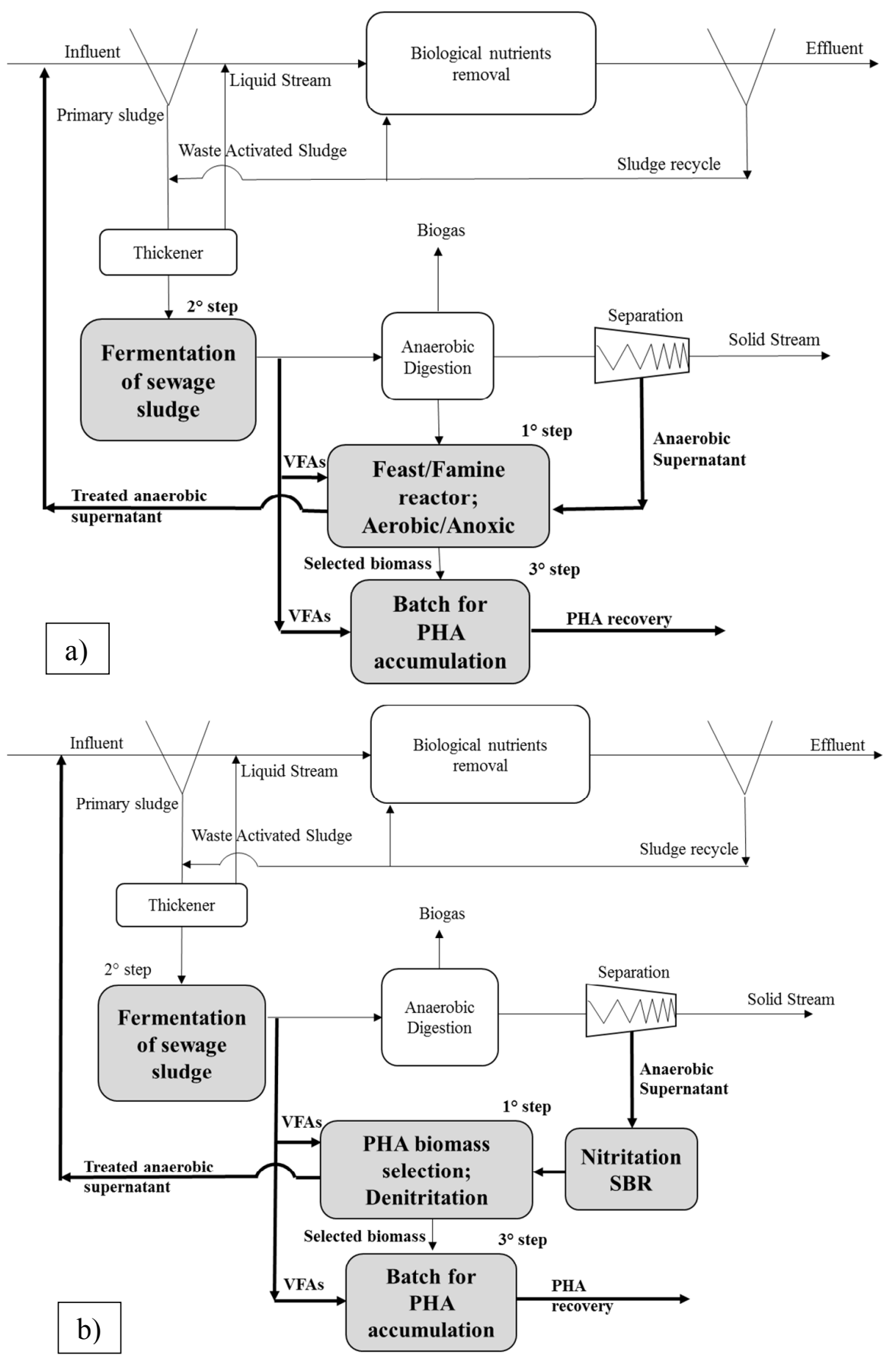

478 Figure 1. Configurations for the combined selection of PHA storing biomass and nitrogen

479 removal from sludge reject water by applying (a) the aerobic/anoxic feast/famine regime and

480 nitrogen removal via nitrite in a single stage reactor and (b) a two-stage process of nitritation

481 (first reactor for the production of electron acceptor) followed by an aerobic/anoxic 482 feast/famine selection reactor. 
483

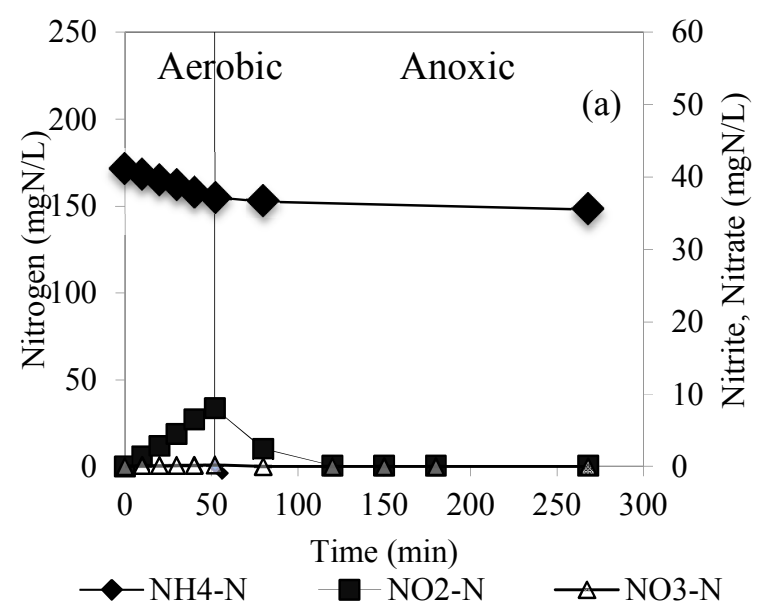

484

(a)

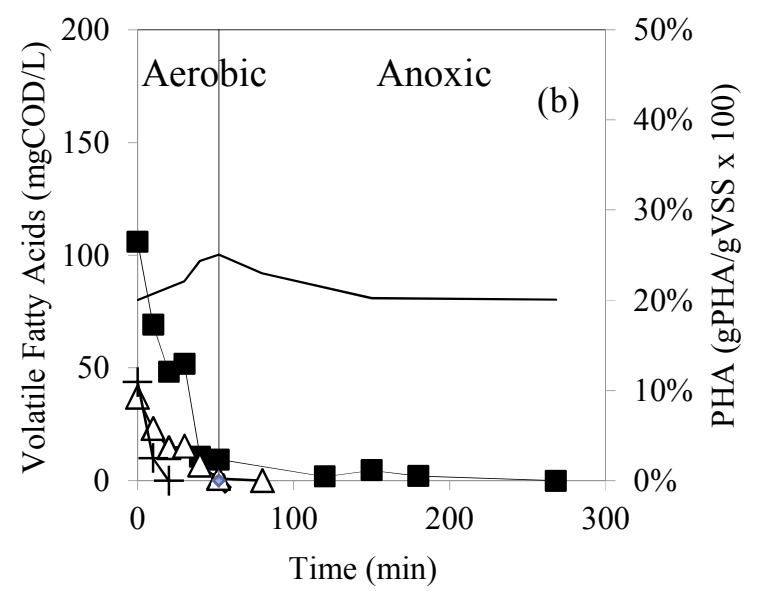

485

(b) $-\mathrm{HAc} \backsim \mathrm{HPr} \longrightarrow \mathrm{HBt} \longrightarrow \mathrm{PHA}$

486 Figure 2. Typical profiles of (a) nitrogen and (b) VFAs and PHA profile during the feast and 487 famine phase of the SBR for period 1 of configuration 1.

488 

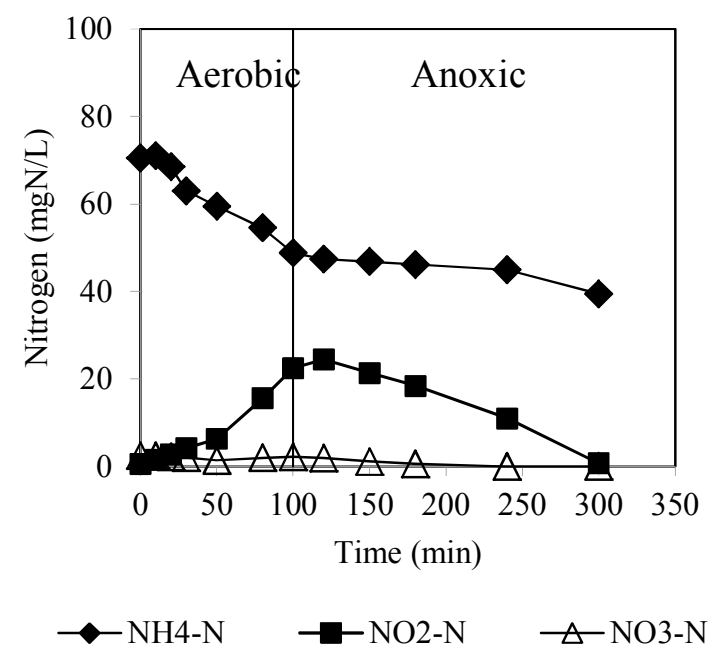

$489 \quad$ (a)

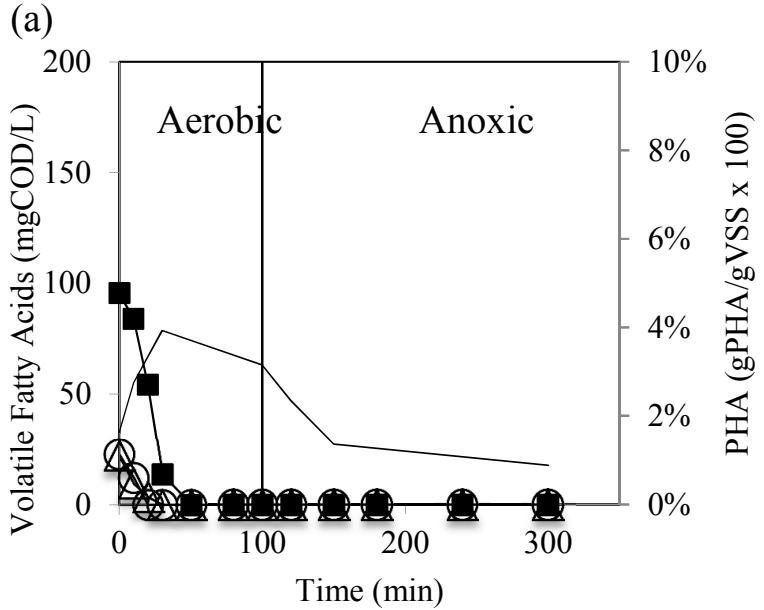

$490 \quad$ (b

491 Figure 3. Typical profiles of (a) nitrogen and (b) VFAs and PHA during the feast and 492 famine phase in the selection reactor during period 2 of configuration 1. 


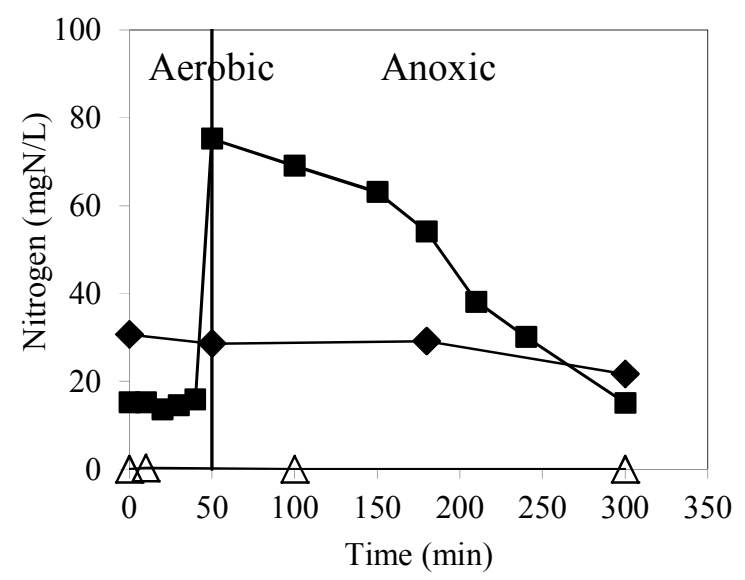

494

(a)
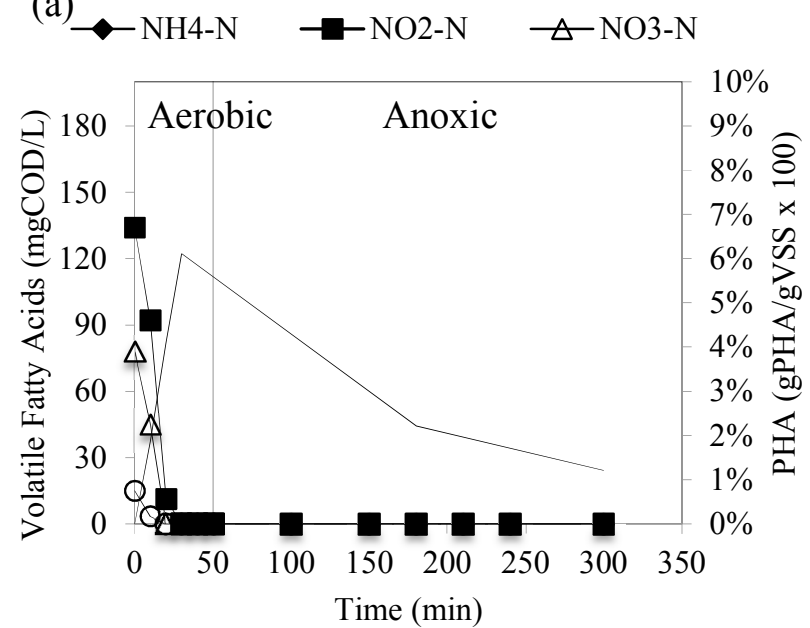

(b)

495

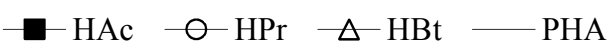

496 Figure 4. Typical profiles of (a) nitrogen and (b) VFAs and PHA during a cycle of the 497 selection SBR in configuration 2.

498 


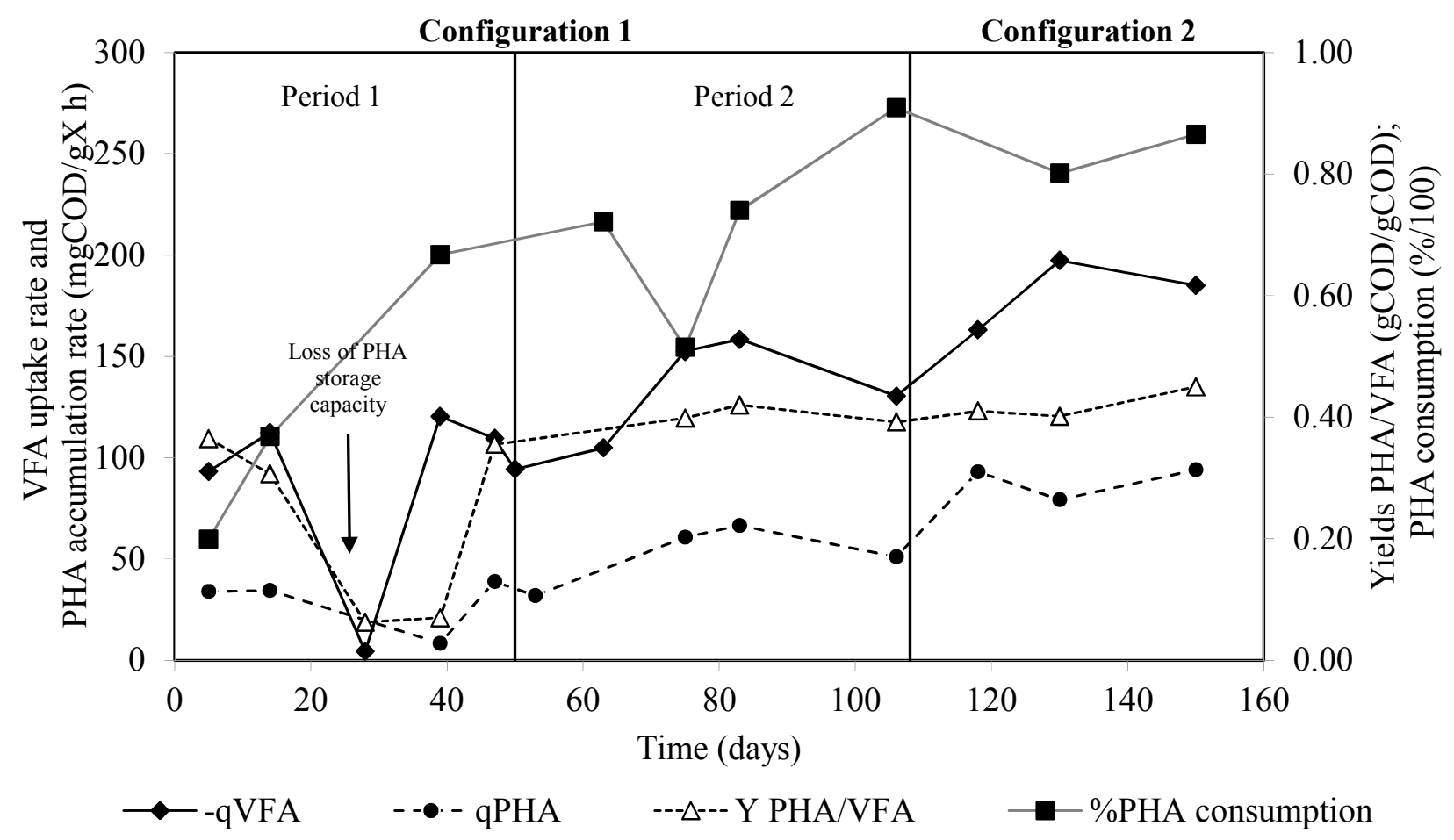

500 Figure 5. -qVFA, qPHA, $\mathrm{Y}_{\mathrm{PHA} / \mathrm{VFA}}$ and efficiency of PHA consumption during the overall

501 experimental periods of configurations 1 and 2

502

503 
504 Table 1. Operating conditions for the 'selection' SBR that was applied for the examined 505 configurations.

\begin{tabular}{cccc}
\hline & \multicolumn{2}{c}{ Configuration 1 } & $\begin{array}{c}\text { Configuration 2 } \\
\text { Parameter }\end{array}$ \\
\cline { 2 - 3 } & Period 1 (days 0-50) & Period 2 (days 51- & Period 3(days 109- \\
vNLR $\left(\mathrm{gN} / \mathrm{m}^{3} \mathrm{~d}\right)$ & $110 \pm 27$ & $380 \pm 29$ & $138)$ \\
OLR $\left(\mathrm{gCOD} / \mathrm{m}^{3} \mathrm{~d}\right)$ & $623 \pm 55$ & $760 \pm 43$ & $530 \pm 11$ \\
$\mathrm{COD} / \mathrm{N}(\mathrm{gCOD}$ \\
$\left.\mathrm{VFA}: \mathrm{gNH}_{4}-\mathrm{N}\right)$ & $5.6 \pm 0.06$ & $2.0 \pm 0.02$ & $1166 \pm 106$ \\
$\mathrm{~F} / \mathrm{M}(\mathrm{gCOD}: \mathrm{gX})$ & $0.33 \pm 0.08$ & $0.22 \pm 0.05$ & $2.2 \pm 0.1$ \\
Aerobic reaction time/Anoxic & $0.30 \pm 0.14$ & $0.73 \pm 0.37$ & $0.20 \pm 0.07$ \\
reaction time & & & 0.20 \\
\hline
\end{tabular}

506

507

508 Table 2. Performance of configuration $1 \& 2$ for PHA biomass enrichment; -qVFA: VFA

509 uptake rate, qPHA, PHA accumulation rate, $\mathrm{Y}_{\mathrm{PHA} / \mathrm{VFA}}$, storage PHA yield based on the VFA.

$510 \quad\left({ }^{*} \mathrm{E}_{\mathrm{nn}}\right.$ : nitrifying efficiency upon the nitrificable incoming nitrogen; ${ }^{* *} \mathrm{E}_{\mathrm{dd}}$ : the denitrifying

511 nitrogen efficiency upon the denitrificable nitrogen).

\begin{tabular}{|c|c|c|c|}
\hline \multirow[t]{2}{*}{ Performance } & \multicolumn{2}{|c|}{ Configuration 1} & \multirow[t]{2}{*}{ Configuration 2} \\
\hline & Period 1 & Period 2 & \\
\hline $\operatorname{Enn}(\%)^{*}$ & 39 & 49 & 87 \\
\hline $\operatorname{Edd}(\%)^{* *}$ & 94 & 97 & 89 \\
\hline -qVFA(mgCOD/gX h) & $96 \pm 33$ & $136 \pm 29$ & $182 \pm 14$ \\
\hline qPHA(mgCOD/gX h) & $36 \pm 0.2$ & $53 \pm 9$ & $89 \pm 7$ \\
\hline $\mathrm{Y}_{\mathrm{PHA} / \mathrm{VFA}}\left(\mathrm{mgCOD}_{\mathrm{PHA}} / \mathrm{gCOD}_{\mathrm{VFA}}\right)$ & $230 \pm 15$ & $371 \pm 15$ & $437 \pm 40$ \\
\hline
\end{tabular}

512

513 
514 Table 3. Performance of the batch PHA accumulation using different types of carbon source.

\begin{tabular}{|c|c|c|c|}
\hline Parameter & $\begin{array}{l}\text { Synthetic mixture of } \\
\text { VFA }\end{array}$ & WSFL & SFL \\
\hline Duration of accumulation & 8.5 & 8.5 & 8.5 \\
\hline $\mathrm{COD}(\mathrm{VFA}): \mathrm{NH}_{4}-\mathrm{N}: \mathrm{PO}_{4}-\mathrm{P}$ & 100:0:0 & $100: 7.8: 0.06$ & $100: 9.7: 2.1$ \\
\hline Initial/Final* $\mathrm{NH}_{4}-\mathrm{N}(\mathrm{mgN} / \mathrm{L})$ & $35.7 / 27.2$ & $20.1 / 185.5$ & $35.2 / 146.5$ \\
\hline Initial/Final* $\mathrm{PO}_{4}-\mathrm{P}(\mathrm{mgP} / \mathrm{L})$ & $12.5 / 8.4$ & $11.6 / 8.1$ & $25.4 / 45.3$ \\
\hline$\%$ PHAs (gPHA/gVSS x 100) & $44 \pm 5 \%$ & $21 \pm 2 \%$ & $19 \pm 2 \%$ \\
\hline $\mathrm{HAc} / \mathrm{HPr}(\mathrm{gCOD} / \mathrm{gCOD})$ & 1.4 & 1.1 & 1.1 \\
\hline $\mathrm{HV}(\%)$ & $65(\mathrm{HV}+\mathrm{HH})$ & 41 & 42 \\
\hline $\mathrm{Y}_{\mathrm{PHA} / \mathrm{VFA}}(\mathrm{gCOD} / \mathrm{gCOD})$ & $0.46 \pm 0.06$ & $0.40 \pm 0.04$ & $0.40 \pm 0.04$ \\
\hline $\mathrm{Y}_{\mathrm{X} / \mathrm{VFA}}(\mathrm{gCOD} / \mathrm{gCOD})$ & $0.26 \pm 0.02$ & $0.25 \pm 0.09$ & $0.23 \pm 0.06$ \\
\hline
\end{tabular}

$5 \overline{15}$

516 Table 4. Main properties of the biopolymers obtained with the different carbon sources after

517 the accumulation tests.

\begin{tabular}{llllllll}
\hline Carbon source & $\begin{array}{l}\mathrm{Mw} \\
(\mathrm{g} / \mathrm{mol})\end{array}$ & $\begin{array}{l}\mathrm{PDI} \\
(\mathrm{Mw} / \mathrm{Mn})\end{array}$ & $\begin{array}{l}\mathrm{Tg} \\
\left({ }^{\circ} \mathrm{C}\right)\end{array}$ & $\begin{array}{c}\mathrm{T}_{\mathrm{m} 1} \\
\left({ }^{\circ} \mathrm{C}\right)\end{array}$ & $\begin{array}{l}\mathrm{T}_{\mathrm{m} 2} \\
\left({ }^{\circ} \mathrm{C}\right)\end{array}$ & $\begin{array}{l}\Delta \mathrm{Hm} \\
(\mathrm{J} / \mathrm{g})\end{array}$ & $\mathrm{T}_{\mathrm{d} \text {-trans }}\left({ }^{\circ} \mathrm{C}\right)$ \\
\hline Synthetic mixture of VFA & $6.2 \times 10^{5}$ & 1.30 & -1.1 & 138 & 147 & 21 & 267 \\
SFL & $6.5 \times 10^{5}$ & 1.29 & -0.5 & 136 & 144 & 24 & 275 \\
WSFL & $7.4 \times 10^{5}$ & 1.25 & -1.6 & 141 & 153 & 27 & 276 \\
\hline
\end{tabular}

518 Mw: average molecular weight, PDI: polydispersity index, Mn: molar number, Td-trans:

519 decomposition temperature (DSC analyses), Tg: glass-transition temperature, Tm: melting

520 temperature, $\Delta \mathrm{Hm}$ : melting enthalpy

521

522 